Article

\title{
Accuracy Evaluation of Geoid Heights in the National Control Points of South Korea Using High-Degree Geopotential Model
}

\author{
Kwang Bae Kim ${ }^{1} * \mathbb{\infty}$, Hong Sik Yun ${ }^{1}$ and Ha Jung Choi ${ }^{2}$ \\ 1 School of Civil, Architectural, and Environmental System Engineering, Sungkyunkwan University, \\ Suwon 16419, Korea; yoonhs@skku.edu \\ 2 Interdisciplinary Program for Crisis, Disaster, and Risk Management, Sungkyunkwan University, \\ Suwon 16419, Korea; mollich@naver.com \\ * Correspondence: kbkim929@skku.edu; Tel.: +82-31-299-4251
}

Received: 9 December 2019; Accepted: 18 February 2020; Published: 21 February 2020

\begin{abstract}
Precise geoid heights are not as important for understanding Earth's gravity field, but they are important to geodesy itself, since the vertical datum is defined as geoid in a cm-level accuracy. Several high-degree geopotential models have been derived lately by using satellite tracking data such as those from Gravity Recovery and Climate Experiment (GRACE) and Gravity Field and Steady-State Ocean Circulation Explorer (GOCE), satellite altimeter data, and terrestrial and airborne gravity data. The Korean national geoid (KNGeoid) models of the National Geographic Information Institute (NGII) were developed using the latest global geopotential models (GGMs), which are combinations of gravity data from satellites and land gravity data. In this study, geoid heights calculated from the latest high-degree GGMs were used to evaluate the accuracy of the three GGMs (European Improved Gravity model of Earth by New techniques (EIGEN)-6C4, Earth Gravitational Model 2008 (EGM2008), and GOCE-EGM2008 combined model (GECO)) by comparing them with the geoid heights derived from the Global Navigation Satellite System (GNSS)/leveling of the 1182 unified control points (UCPs) that have been installed by NGII in South Korea since 2008. In addition, the geoid heights derived from the KNGeoid models were compared with the geoid heights derived from the GNSS/leveling of the 1182 UCPs to assess the accuracy of the KNGeoid models in terms of relative geoid heights for further gravimetric geoid determination studies in South Korea. As a result, the EGM2008 model could be selected as the suitable GGM from among the three GGMs for determining a gravimetric geoid model for South Korea.
\end{abstract}

Keywords: Korean national geoid; GNSS/leveling-derived geoid height; unified control points; global geopotential model

\section{Introduction}

Geoid, which approximates the mean sea level (MSL), is a reference surface for determining topographic heights and ocean depths. It is necessary to establish a geoid model based on continuous gravity observations, because geoid represents the Earth's shape resulting from the mass distributions above and below the Earth's surface. The global geopotential models (GGMs) derived from the data obtained by Gravity Recovery and Climate Experiment (GRACE) launched in 2002 have been released. Earth Gravitational Model 96 (EGM96) [1], European Improved Gravity model of Earth by New techniques (EIGEN)-CG01C [2], EIGEN-CG03C [3], and Earth Gravitational Model 2008 (EGM2008) [4] were used for geoid model establishment in South Korea, and the accuracy of the EGM2008 model was evaluated using the Global Navigation Satellite System (GNSS)/leveling data [5-9]. Assessment of 
geoid height accuracy is necessary for determining the high-degree GGMs that have the best fit to GNSS/leveling data in national control points over South Korea.

The recently released GGMs were based on gravity data obtained from the Gravity Field and Steady-State Ocean Circulation Explorer (GOCE) gravitational exploration satellite launched in 2009. Several GGMs have been calculated using satellite tracking data from the GRACE and GOCE gravity missions [10,11]. High-degree geopotential models of spherical harmonic coefficients are used for modeling the Earth's exterior gravity field. Such coefficients are derived from satellite tracking data, altimeter data, and terrestrial and airborne gravity data. Hundreds of thousands of coefficients and standard deviation values for these coefficients are estimated through millions of measurements. The number and distribution of measurements, as well as the type of measurement, affect the accuracy of a geopotential model. Since the 1960s, satellite gravity field missions have provided accurate data for forming geopotential models and these models have been evaluated based on the data provided by the satellite gravity field missions.

The National Geographic Information Institute (NGII) has developed three Korean national geoid (KNGeoid) models-KNGeoid13, KNGeoid14, and KNGeoid18-using the Earth's gravity field model, satellite-altimetry-derived gravity data, land and ocean gravity data, airborne gravity data, and digital elevation model (DEM) data. The KNGeoid models are hybrid geoid models developed by NGII to improve the height measurement accuracy based on GNSS surveying.

First, the KNGeoid13 model, developed by NGII for the land part, was based on gravity data obtained from several national control points (unified control point (UCP), benchmark (BM), triangulation point), airborne gravity data obtained since 2008, DTU10 satellite altimeter data [12], EGM2008 data, and $5 \mathrm{~m}$ gridded topographic data. The standard deviation of residuals of the KNGeoid13 model are $3.41 \mathrm{~cm}$ [13]. Second, the KNGeoid14 model was developed using the same method utilized for developing the KNGeoid13 model, by adding the gravity data obtained in 2014 and shipborne gravity data from the Korea Hydrographic and Oceanographic Agency (KHOA, http://www.khoa.go.kr) to the gravity data constructed on KNGeoid13, and its standard deviation of residuals was evaluated as approximately $3.3 \mathrm{~cm}$ [14]. Finally, the KNGeoid18 model was developed using Experimental Gravity Field Model 2016 (XGM2016) based on the GOCE gravity data [15] generated as the initial version of Earth Gravitation Model 2020 (EGM2020), and its standard deviation of residuals is $2.33 \mathrm{~cm}$ [16].

The development of geoid model based on the longer wavelength part of the geoid derived from the EGM2008 has been performed. Several studies have implemented accuracy evaluation of geoid heights derived from GGMs by comparing them with the GNSS/leveling geoid height data obtained in the national control points (BM and UCP) of South Korea [5-9].

The EGM2008 is a spherical harmonic model of the Earth's gravitational potential developed through a least-squares combination of the ITG-GRACE03S gravitational model and its associated error covariance matrix, with the gravitational information obtained from a global set of area-mean free-air gravity anomalies defined on a 5' equiangular grid [4]. The EGM2008 is complete to degree and order 2159 and contains additional coefficients up to degree 2190 and order 2159. The EIGEN-6C4 [17], the newest ultra-high-degree global gravity field model, is the latest release in the EIGEN-6C series, containing the complete satellite gravity gradiometry (SGG) data of the GOCE mission. The GOCE-EGM2008 combined model (GECO) [18] is a global gravity model which is computed by incorporating the GOCE-only TIM-R5 solution, which is the fifth release (R5) of the time-wise (TIM) model, into the EGM2008. The EGM2008 geoid undulations are computed on a global spherical grid with a $0.5^{\circ}$ resolution by synthesizing the EGM2008 coefficients up to degree 359 . The GOCE geoid on the same grid is computed by synthesizing the TIM-R 5 coefficients, up to degree 250 . Finally, the GECO spherical harmonic coefficients are computed by analyzing the combined global geoid grid up to degree 359 (consistently with the $0.5^{\circ}$ resolution). From degrees 360 to 2190, the GECO coefficients are the same as those of EGM2008. The GECO coefficient errors are computed as the weighted average of the coefficient errors of EGM2008 and the TIM-R5 solution [18]. 
Once the latest high-degree global gravitational field model has been developed and published, precision analysis is performed to determine its utility. The International Center for Global Earth Models (ICGEM, http://icgem.gfz-potsdam.de/home), operated by GFZ in Germany, receives the GNSS/leveling data from Australia, Brazil, Canada, Europe, Japan, and USA, and performs a local precision analysis. Table 1 represents the precision levels of the three GGMs that were used in this study. The precision levels are root-mean-square-error of the mean differences between the GNSS/levelling-derived geoid heights and the model-computed geoid heights. It is open to the public.

Table 1. Precision levels of the GGMs used in this study [19].

\begin{tabular}{ccccc}
\hline \multirow{2}{*}{ Country/Region } & \multirow{2}{*}{ GNSS/Leveling Data Points } & \multicolumn{2}{c}{ Global Geopotential Models (N $\max$ ) } \\
\cline { 3 - 4 } & & EGM2008 (2190) & EIGEN-6C4 (2190) & GECO (2190) \\
\hline Australia & 201 & $21.7 \mathrm{~cm}$ & $21.2 \mathrm{~cm}$ & $21.6 \mathrm{~cm}$ \\
Brazil & 1112 & $46.0 \mathrm{~cm}$ & $44.6 \mathrm{~cm}$ & $45.1 \mathrm{~cm}$ \\
Canada & 2691 & $12.8 \mathrm{~cm}$ & $12.6 \mathrm{~cm}$ & $13.1 \mathrm{~cm}$ \\
Europe & 1047 & $12.5 \mathrm{~cm}$ & $12.1 \mathrm{~cm}$ & $12.3 \mathrm{~cm}$ \\
Japan & 816 & $8.3 \mathrm{~cm}$ & $7.9 \mathrm{~cm}$ & $8.0 \mathrm{~cm}$ \\
USA & 6169 & $24.8 \mathrm{~cm}$ & $24.7 \mathrm{~cm}$ & $24.6 \mathrm{~cm}$ \\
All & 12,036 & $23.97 \mathrm{~cm}$ & $23.61 \mathrm{~cm}$ & $23.71 \mathrm{~cm}$ \\
\hline
\end{tabular}

The aim of this study was to evaluate the accuracy of the geoid heights derived from the latest high-degree GGMs developed based on satellite gravity data such as those from GRACE and GOCE as compared with the GNSS/leveling-derived geoid heights of the 1182 UCPs that have been installed by NGII in South Korea since 2008, as shown in Figure 1. In addition, the geoid heights derived from the KNGeoid models were compared with the GNSS/leveling-derived geoid heights of the 1182 UCPs to assess the accuracy of the gravimetric geoid models in terms of relative geoid heights to GNSS/leveling data for further gravimetric geoid determination studies in South Korea.

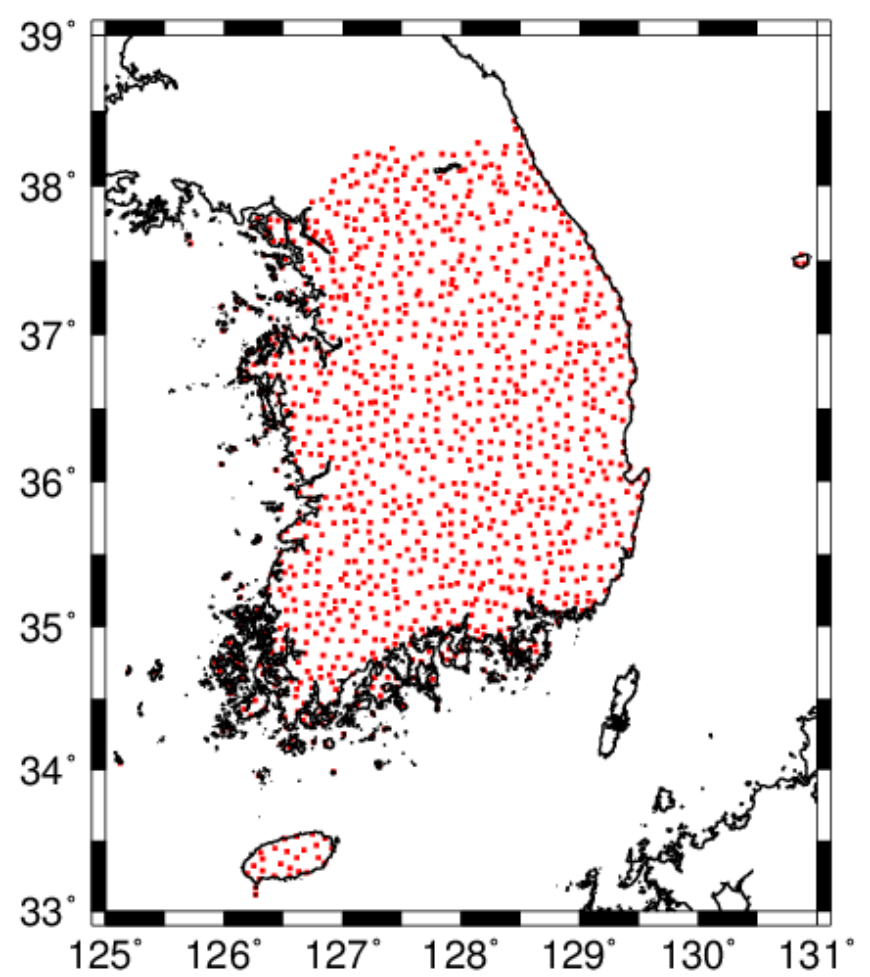

Figure 1. Location map of the 1182 GNSS/leveling UCPs in South Korea that were used in this study for the evaluation of the geoid heights in the study area. 


\section{Materials and Methods}

\subsection{Study Area}

In the first UCP construction project of NGII between 2008 and 2010, 1196 points were installed at $10 \mathrm{~km}$ intervals across the country. GNSS surveying, precise leveling, and gravity surveying were performed to provide the necessary three-dimensional survey results. A UCP is a new national control point built to maximize the surveying efficiency, such as the convenience, by integrating the national control point functions that were installed and managed individually (triangulation point, BM, gravity point, etc.).

In this study, the geoid heights derived from the high-degree GGMs and KNGeoid models were evaluated by utilizing the geometric geoid heights obtained from the GNSS/leveling on 1182 of the 1196 UCPs installed by NGII between 2008 and 2010, in South Korea. Figure 1 shows the location map of the 1182 GNSS/leveling UCPs that were used for the evaluation of the geoid heights in the study area $\left(125^{\circ}\right.$ to $131^{\circ} \mathrm{E}, 33^{\circ}$ to $\left.39^{\circ} \mathrm{N}\right)$, which includes the inland and islands of South Korea.

\subsection{Geoid Height Computation from GGMs}

For global gravity field analysis, a spherical harmonic series can represent the geoid heights $(N)$. The longer wavelength geoid heights $(N)$ contributed by the geopotential models were computed at position $\left(\varphi_{P}, \lambda_{P}\right)$ using Equation (1) [20]:

$$
N\left(\varphi_{P}, \lambda_{P}\right)=R \sum_{l=2}^{L} \sum_{m=0}^{l}\left[\bar{C}_{l m} \cos m \lambda_{P}+\bar{S}_{l m} \sin m \lambda_{P}\right] \bar{P}_{l m}\left(\sin \varphi_{P}\right)
$$

where $R$ is the Earth's mean radius; $\bar{C}_{l m}$ and $\bar{S}_{l m}$ are the fully normalized spherical harmonic coefficients; $\bar{P}_{l m}\left(\sin \varphi_{P}\right)$ is the fully normalized associated Legendre function; and $l$ and $m$ are the degree and order, respectively.

The finite series is usually truncated at the maximum degree of expansion $l=L$. The series coefficients allow the determination of geoid heights using Equation (1).

Table 2 summarizes the main characteristics of the three high-degree GGMs that were utilized in this study. In Table 2, $S$ stands for satellite (e.g., GRACE, GOCE, and LAGEOS), A for altimetry, and G for ground data (e.g., terrestrial, shipborne, and airborne measurements).

Table 2. Characteristics of the GGMs used in this study.

\begin{tabular}{cccc}
\hline Geopotential Model & Year & Max. Degree & Data Type \\
\hline GECO & 2016 & 2190 & S (GOCE), EGM2008 \\
EIGEN-6C4 & 2014 & 2190 & S (GOCE, GRACE, LAGEOS), A, G \\
EGM2008 & 2008 & 2190 & S (GRACE), A, G \\
\hline
\end{tabular}

The GGMs that were used in this study, as shown in Table 2, were provided by ICGEM in the zero-tide system with respect to a geometrically fixed GRS80 reference ellipsoid, and were calculated from GRACE and GOCE gravitational satellite observations, satellite-altimetry-derived gravity data, land gravity data, etc. For the geoid height accuracy evaluation in this study, high-degree GGMs developed from the combined contributions of various types of satellite tracking data, gravity data, and satellite altimetry data were considered, as shown in Table 2 . The geoid heights $\left(N_{G G M}\right)$ obtained through spherical harmonic synthesis from high-degree GGMs were interpolated into the 1182 GNSS/leveling UCPs to assess the accuracy of geoid heights derived from the three different GGMs with maximum degree 2190.

The GNSS/leveling geoid heights $\left(N_{\text {GNSS / leveling }}\right)$ at the 1182 UCPs were computed by subtracting the known orthometric height $\left(H_{\text {leveling }}\right)$ calculated from the precise leveling between the BM and the 
UCP from the known ellipsoidal height $\left(h_{\text {GNSS }}\right)$ obtained through GNSS observations, as given in Equation (2).

$$
N_{G N S S / \text { leveling }}=h_{G N S S}-H_{\text {leveling }} \text {. }
$$

The GNSS-derived geoid heights are invariably different from the values interpolated from a gravimetrically derived geoid model, and are influenced by the datum inconsistencies, biases, and errors associated with the independently derived ellipsoidal and orthometric height data [21-24]. An external evaluation of the quality of a gravimetric geoid model or GGM can be performed by comparing its interpolated values $\left(N_{i}^{\text {Model }}\right)$ at the 1182 UCPs with the corresponding GNSS/leveling-derived geoid heights $\left(N_{i}^{\text {GNSS/leveling }}\right)$. Such a comparison is conventionally based on the following model, as given in Equation (3) [22,23]:

$$
\Delta N_{i}=N_{i}^{G N S S / l e v e l i n g}-N_{i}^{\text {Model }}=h_{i}-H_{i}-N_{i}
$$

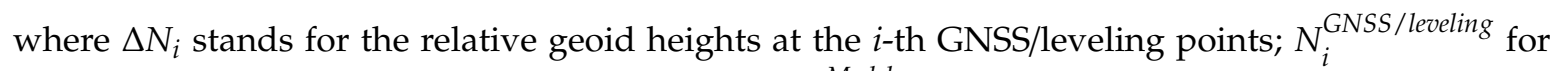
the GNSS/leveling geoid heights at the $i$-th points; $N_{i}^{M o d e l}$ for the geoid heights interpolated into the GNSS/leveling points from the gravimetric geoid models and GGMs; $h_{i}, H_{i}$, and $N_{i}$ for the ellipsoidal height, orthometric height, and geoid height, respectively, at the $i$-th GNSS/leveling points.

\section{Results and Discussions}

In this study, the geoid heights in South Korea were first calculated from the three KNGeoid models and three GGMs to evaluate the accuracy of the geoid models on the 1182 GNSS/leveling UCPs installed by NGII, as shown in Figure 1. Figures 2 and 3 show the $1^{\prime}$ gridded geoid heights derived from the GGMs (maximum degree 2190) and from the KNGeoid models developed by NGII, respectively. The 1' gridded geoid height maps were computed using the "surface" routine, which is a continuous curvature surface gridding algorithm, of Generic Mapping Tools (GMT, htpp://gmt.soest.hawaii.edu) [25]. The geoid heights derived from the three GGMs ranged from 18.0 to $33.4 \mathrm{~m}$, as shown in Figure 2. In Figure 3, the geoid heights derived from the three KNGeoid models are distributed between 17.8 and $33.3 \mathrm{~m}$.

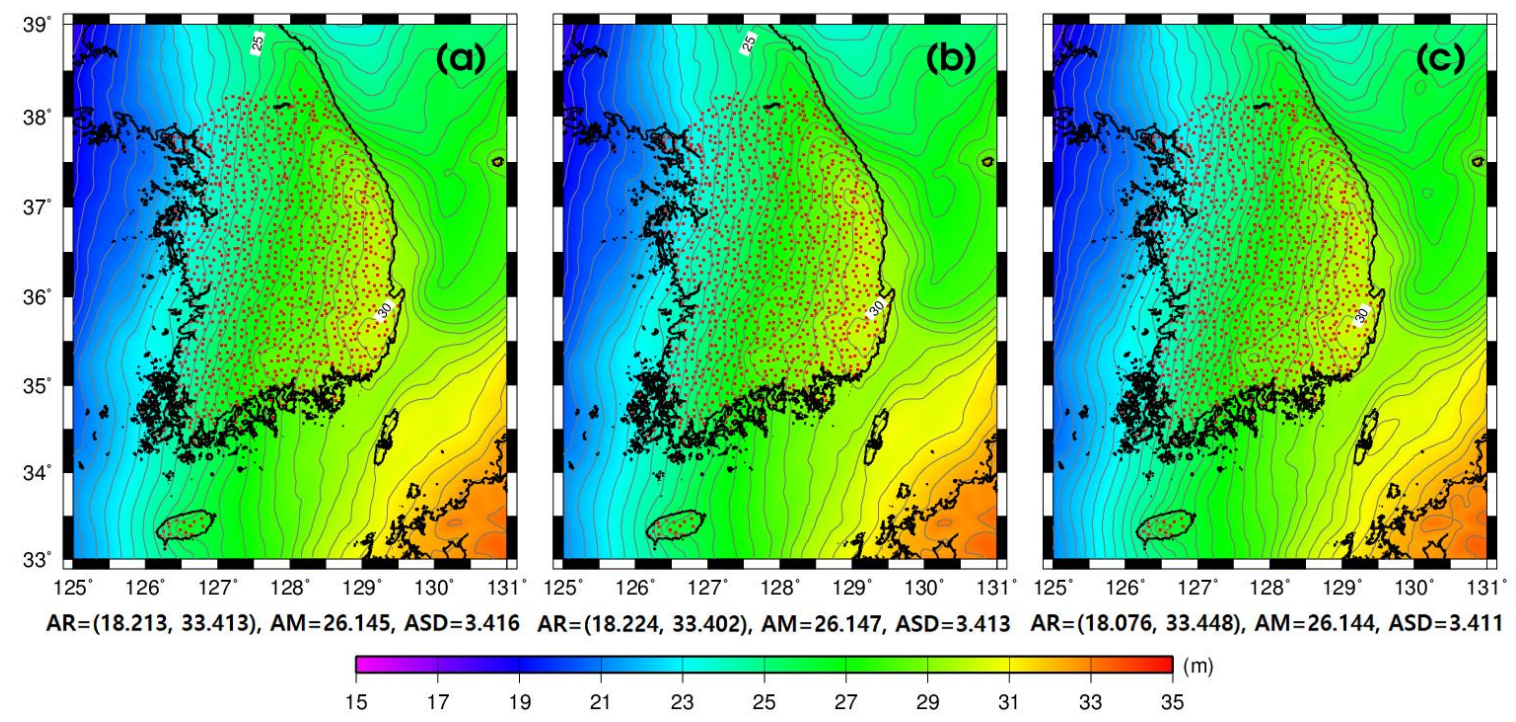

Figure 2. The $1^{\prime}$ gridded geoid height $\left(N_{G G M}\right)$ derived from the three GGMs (max. degree 2190). (a) GECO; (b) EIGEN-6C4; and (c) EGM2008. The attributes listed for this and subsequent maps include the amplitude range ( $\mathrm{AR}=$ minimum and maximum values), amplitude mean (AM), and amplitude standard deviation (ASD). The red dots represent the locations of the 1182 GNSS/leveling UCPs.

The three GGMs were interpolated into the GNSS/leveling data locations of the 1182 UCPs, which are shown as red dots in Figure 1, to evaluate the accuracy of the geoid heights derived from the three GGMs. Figure 4 shows the $1^{\prime}$ gridded residual surface maps between the geoid heights derived from 
the GNSS/leveling on the 1182 UCPs and those derived from the three GGMs (GECO, EIGEN-6C4, and EGM2008). The statistics of the residual surface maps between the geoid heights $\left(N_{\text {GNSS /leveling }}\right)$ derived from the GNSS/leveling on the 1182 UCPs and those $\left(N_{G G M}\right)$ derived from the three GGMs, shown in Figure 4a-c, respectively, are summarized in Table 3. According to the summarized statistics in Table 3, the geoid heights derived from the three GGMs as compared with those derived from the GNSS/leveling on the 1182 UCPs installed along the western coastal areas of South Korea, shown in Figure $4 \mathrm{a}-\mathrm{c}$, respectively, had a maximum difference of $-1.837 \mathrm{~m}\left(126.425^{\circ} \mathrm{E}, 37.391^{\circ} \mathrm{N}\right)$, in GECO. The RMSE of the residual surface maps between the geoid heights derived from the GNSS/leveling on the 1182 UCPs and those derived from EGM2008, shown in Table 3, is smaller than that of the residual surface maps between the geoid heights derived from the GNSS/leveling on the 1182 UCPs and those derived from GECO, and between the geoid heights derived from the GNSS/leveling on the 1182 UCPs and those derived from EIGEN-6C4.

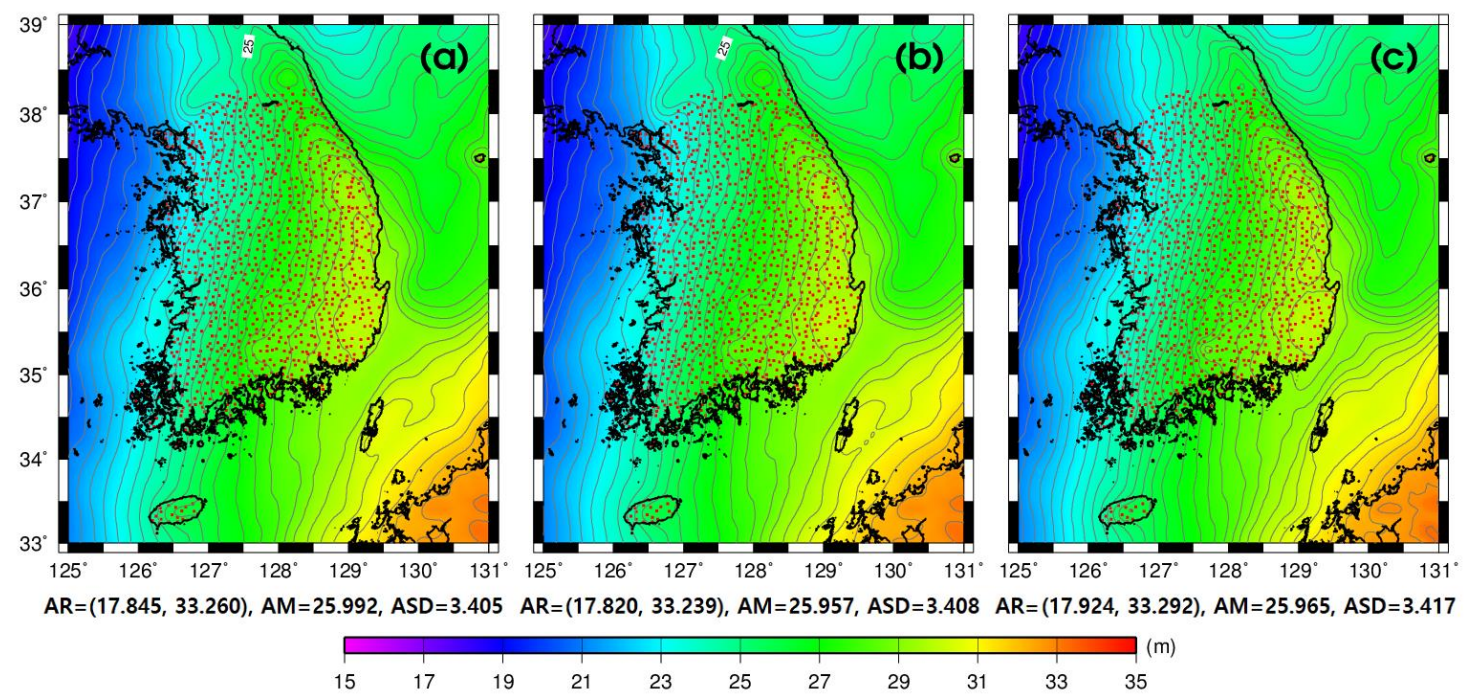

Figure 3. The $1^{\prime}$ gridded geoid heights $\left(N_{K N G e o i d}\right)$ derived from the three KNGeoid models developed by NGII. (a) KNGeoid13; (b) KNGeoid14; and (c) KNGeoid18. The red dots represent the locations of the 1182 GNSS/leveling UCPs.

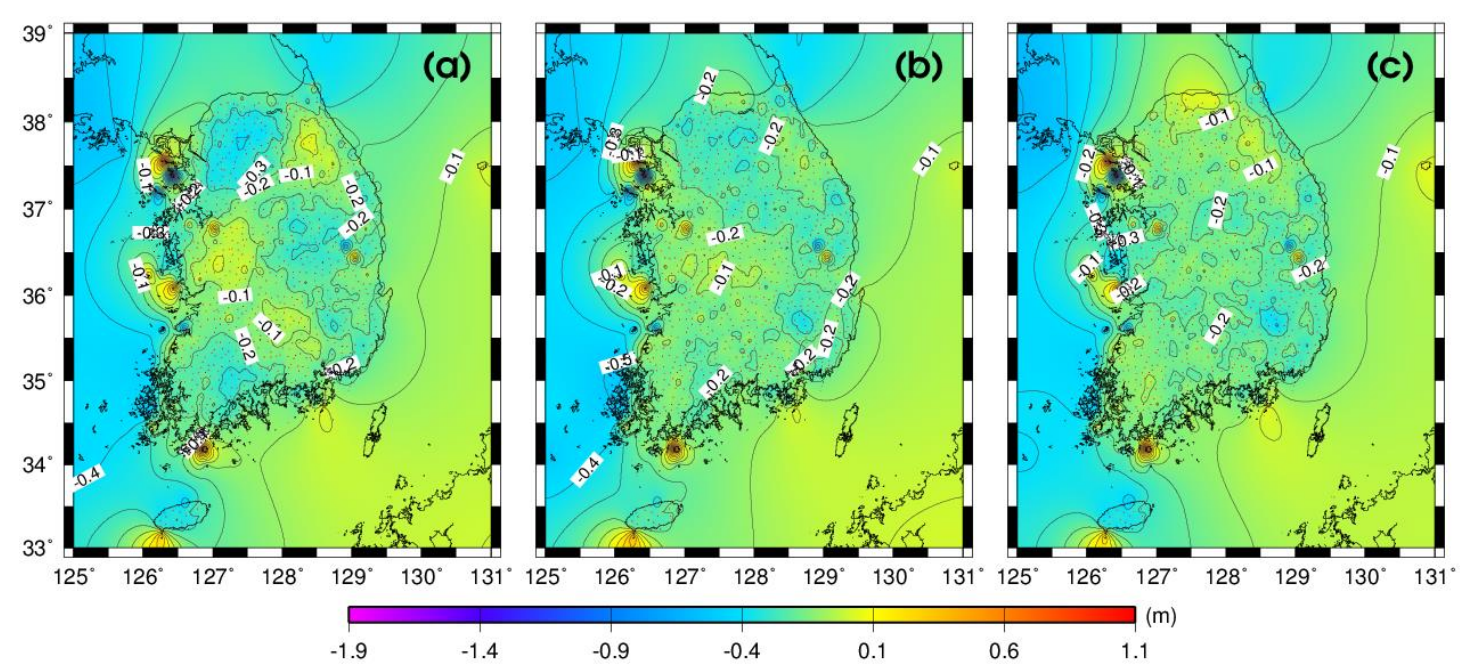

Figure 4. Residual surface maps between the GNSS/leveling-derived geoid heights $\left(N_{G N S S / l e v e l i n g}\right)$ on the 1182 UCPs and those $\left(N_{G G M}\right)$ derived from the three GGMs. (a) GECO; (b) EIGEN-6C4; and (c) EGM2008. The red dots represent the locations of the 1182 GNSS/leveling UCPs. 
Table 3. Statistics of the differences between the geoid heights $\left(N_{\text {GNSS/leveling }}\right)$ derived from the GNSS/leveling on the 1182 UCPs and those $\left(N_{G G M}\right)$ derived from the three GGMs (unit, $\mathrm{m}$ ).

\begin{tabular}{cccccc}
\hline & Min. & Max. & Mean & Std. Dev. & RMSE \\
\hline$N_{\text {GNSS /leveling }}-N_{\text {GECO }}$ & -1.837 & 1.025 & -0.199 & 0.126 & 0.236 \\
$N_{\text {GNSS/leveling }}-N_{E I G E N-6 C 4}$ & -1.817 & 1.010 & -0.191 & 0.112 & 0.221 \\
$N_{\text {GNSS/leveling }}-N_{E G M 2008}$ & -1.801 & 1.012 & -0.184 & 0.113 & 0.216 \\
\hline
\end{tabular}

From the histograms of the differences between the GNSS/leveling-derived geoid heights on the 1182 UCPs and the three GGMs-derived geoid heights presented in Figure 5a-c, the percentage of the absolute values of differences between the GNSS/leveling geoid heights on the 1182 UCPs and the geoid heights derived from the three GGMs was calculated, as shown in Table 4. As can be seen in Table 4, the agreement between the geoid heights derived from the GNSS/leveling on the 1182 UCPs and the EGM2008-derived geoid heights was $62.0 \%$ when the absolute values of differences were $20 \mathrm{~cm}$, whereas for the other GGMs, the consistency level was $49.7 \%$ and $56.9 \%$ for GECO and EIGEN-6C4, respectively. Moreover, more than $90 \%$ of the 1182 UCPs showed an agreement between the EIGEN-6C4- and GNSS/leveling-derived geoid heights and between the EGM2008- and GNSS/leveling-derived geoid heights that is better than $30 \mathrm{~cm}$ as compared with $84.9 \%$ for the GECO GGM. As a result, we concluded that the EGM2008 model is the more suitable GGM from among the three GGMs for determining a suitable gravimetric geoid model for South Korea.
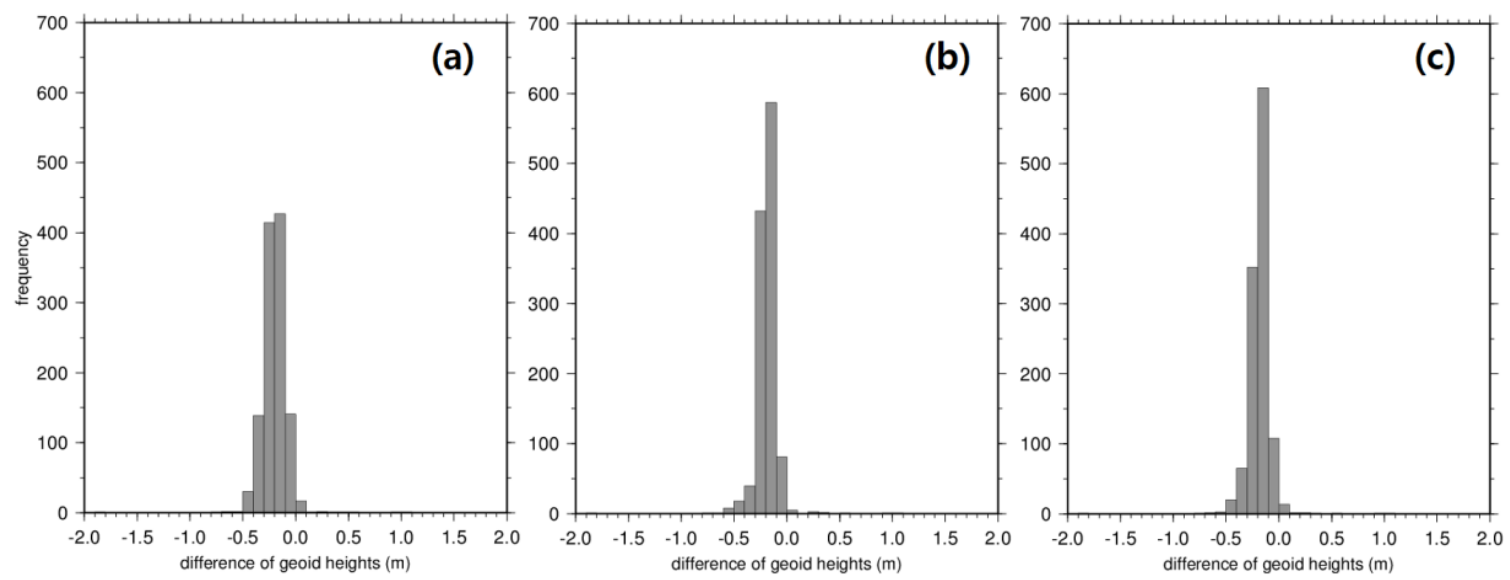

Figure 5. Histograms of the differences between the geoid heights $\left(N_{G N S S} /\right.$ leveling $)$ derived from GNSS/leveling on the 1182 UCPs and the geoid heights $\left(N_{G G M}\right)$ derived from the three KNGeoid models. (a) GECO; (b) EIGEN-6C4; and (c) EGM2008.

Table 4. Percentage of the 1182 UCPs whose absolute values of differences between the geoid heights derived from the GNSS/leveling and those derived from the three GGMs.

\begin{tabular}{ccccccc}
\hline Model & $\leq \mathbf{0 . 0 5} \mathbf{~ m}$ & $\leq \mathbf{0 . 1 0} \mathbf{~ m}$ & $\leq \mathbf{0 . 2 0 ~} \mathbf{~}$ & $\leq \mathbf{0 . 3 0} \mathbf{~ m}$ & $\leq \mathbf{0 . 4 0} \mathbf{~ m}$ & $\leq \mathbf{0 . 5 0} \mathbf{~ m}$ \\
\hline GECO & $71(6.0 \%)$ & $158(13.4 \%)$ & $587(49.7 \%)$ & $1003(84.9 \%)$ & $1142(96.6 \%)$ & $1173(99.2 \%)$ \\
EIGEN-6C4 & $25(2.1 \%)$ & $86(7.3 \%)$ & $673(56.9 \%)$ & $1108(93.7 \%)$ & $1150(97.3 \%)$ & $1168(98.8 \%)$ \\
EGM2008 & $40(3.4 \%)$ & $122(10.3 \%)$ & $733(62.0 \%)$ & $1086(91.9 \%)$ & $1152(97.5 \%)$ & $1172(99.1 \%)$ \\
\hline
\end{tabular}

In addition, for the assessment of the geoid heights of the KNGeoid models, the three KNGeoid models were interpolated into the GNSS/leveling data locations of the 1182 UCPs, which are shown as red dots in Figure 1. Figure 6 shows the $1^{\prime}$ gridded residual surface maps between the GNSS/leveling geoid heights $\left(N_{\text {GNSS /leveling }}\right)$ of the 1182 UCPs and the geoid heights $\left(N_{\text {KNGeoid }}\right)$ derived from the three KNGeoid models (KNGeoid13, KNGeoid14, and KNGeoid18). 


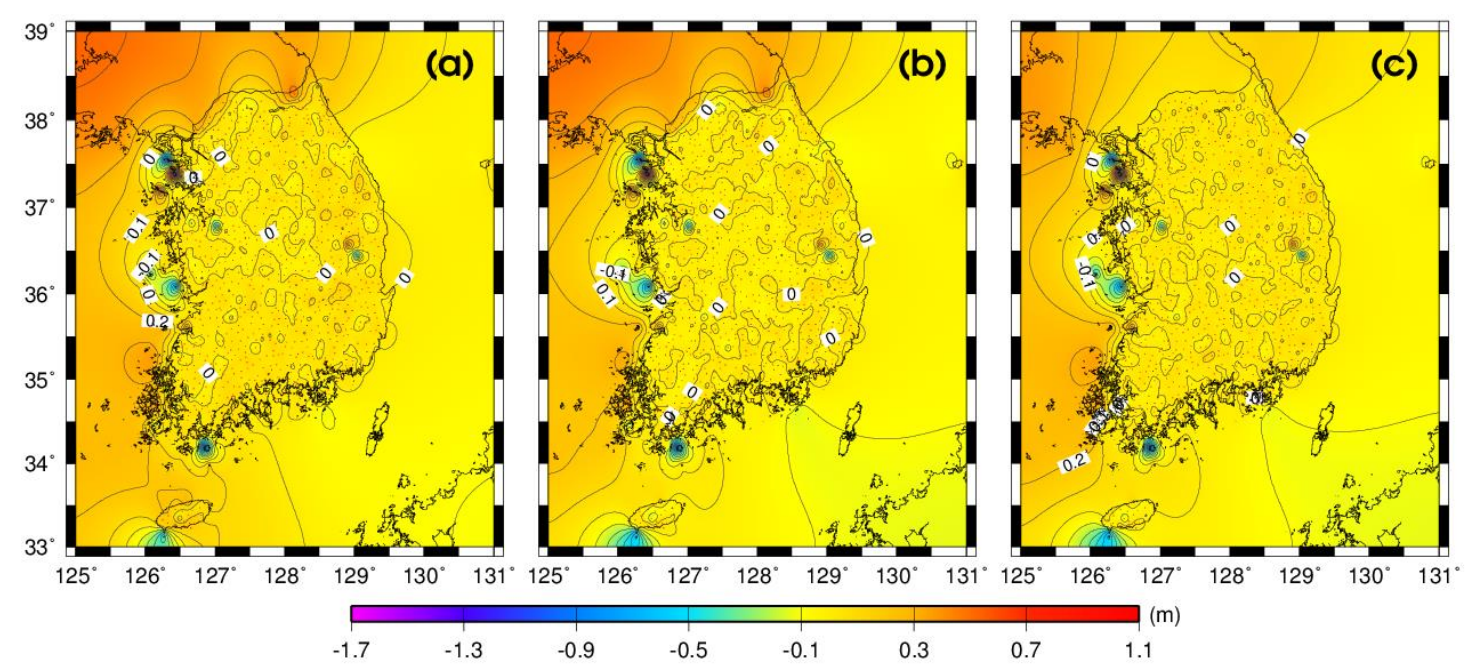

Figure 6. Residual surface maps between the GNSS/leveling-derived geoid heights $\left(N_{G N S S / l e v e l i n g}\right)$ on the 1182 UCPs and those $\left(N_{\text {KNGeoid }}\right)$ derived from the three KNGeoid models. (a) KNGeoid13; (b) KNGeoid14; and (c) KNGeoid18. The red dots represent the locations of the 1182 GNSS/leveling UCPs.

The statistics of the differences between the geometric geoid heights derived from GNSS/leveling on the 1182 UCPs and the geoid heights derived from the three KNGeoid models are represented as shown in Table 5. The differences between the GNSS/leveling geoid heights and the KNGeoid18 geoid heights represent good agreement with the smallest RMSE $(10.3 \mathrm{~cm})$ in Table 5.

Table 5. Statistics of the differences between the geoid heights $\left(N_{G N S S / l e v e l i n g}\right)$ derived from the GNSS/leveling on the 1182 UCPs and those $\left(N_{K N G e o i d}\right)$ derived from the three KNGeoid models (unit: $\mathrm{m}$ ).

\begin{tabular}{lccccc}
\hline & Min. & Max. & Mean & Std. dev. & RMSE \\
\hline$N_{\text {GNSS/leveling }}-N_{\text {KNGeoid13 }}$ & -1.749 & 1.061 & -0.033 & 0.107 & 0.112 \\
$N_{\text {GNSS/leveling }}-N_{\text {KNGeoid14 }}$ & -1.707 & 1.097 & -0.001 & 0.106 & 0.106 \\
$N_{\text {GNSS/leveling }}-N_{\text {KNGeoid18 }}$ & -1.770 & 1.066 & -0.015 & 0.102 & 0.103 \\
\hline
\end{tabular}

Table 6 presents the percentage of the absolute values of differences between the GNSS/leveling geoid heights on the 1182 UCPs and the geoid heights derived from the three KNGeoid models. From the histograms of the differences between the GNSS/leveling-derived geoid heights on the 1182 UCPs and the three KNGeoid model-derived geoid heights presented in Figure $7 \mathrm{a}-\mathrm{c}$, it is known that $88.6 \%$ of the absolute values of differences between the GNSS/leveling-derived geoid heights on the 1182 UCPs and the KNGeoid13-derived geoid heights were below $10.0 \mathrm{~cm}$, whereas $91.3 \%$ and $93.7 \%$ of the differences between the GNSS/leveling-derived geoid heights on the 1182 UCPs and the KNGeoid14and KNGeoid18-derived geoid heights, respectively, were less than $10.0 \mathrm{~cm}$. On the basis of the small differences between the GNSS/leveling-derived geoid heights on the 1182 UCPs and the KNGeoid18 model-derived geoid heights, it was concluded that the most recently developed KNGeoid18 model is better than the KNGeoid13 and KNGeoid14 models as a gravimetric geoid model for South Korea.

Table 6. Percentage of the 1182 UCPs whose absolute values of differences between the geoid heights derived from the GNSS/leveling and those derived from the three KNGeoid models.

\begin{tabular}{ccccccc}
\hline Model & $\leq \mathbf{0 . 0 2} \mathbf{~ m}$ & $\leq \mathbf{0 . 0 5} \mathbf{~ m}$ & $\leq \mathbf{0 . 1 0} \mathbf{~}$ & $\leq \mathbf{0 . 1 5} \mathbf{~ m}$ & $\leq \mathbf{0 . 2 0} \mathbf{~ m}$ & $\leq \mathbf{0 . 5 0} \mathbf{~ m}$ \\
\hline KNGeoid13 & $352(29.8 \%)$ & $764(64.6 \%)$ & $1047(88.6 \%)$ & $1107(93.7 \%)$ & $1128(95.4 \%)$ & $1174(99.3 \%)$ \\
KNGeoid14 & $471(39.8 \%)$ & $899(76.1 \%)$ & $1079(91.3 \%)$ & $1119(94.7 \%)$ & $1133(95.9 \%)$ & $1173(99.2 \%)$ \\
KNGeoid18 & $549(46.4 \%)$ & $950(80.4 \%)$ & $1108(93.7 \%)$ & $1131(95.7 \%)$ & $1141(96.5 \%)$ & $1173(99.2 \%)$ \\
\hline
\end{tabular}



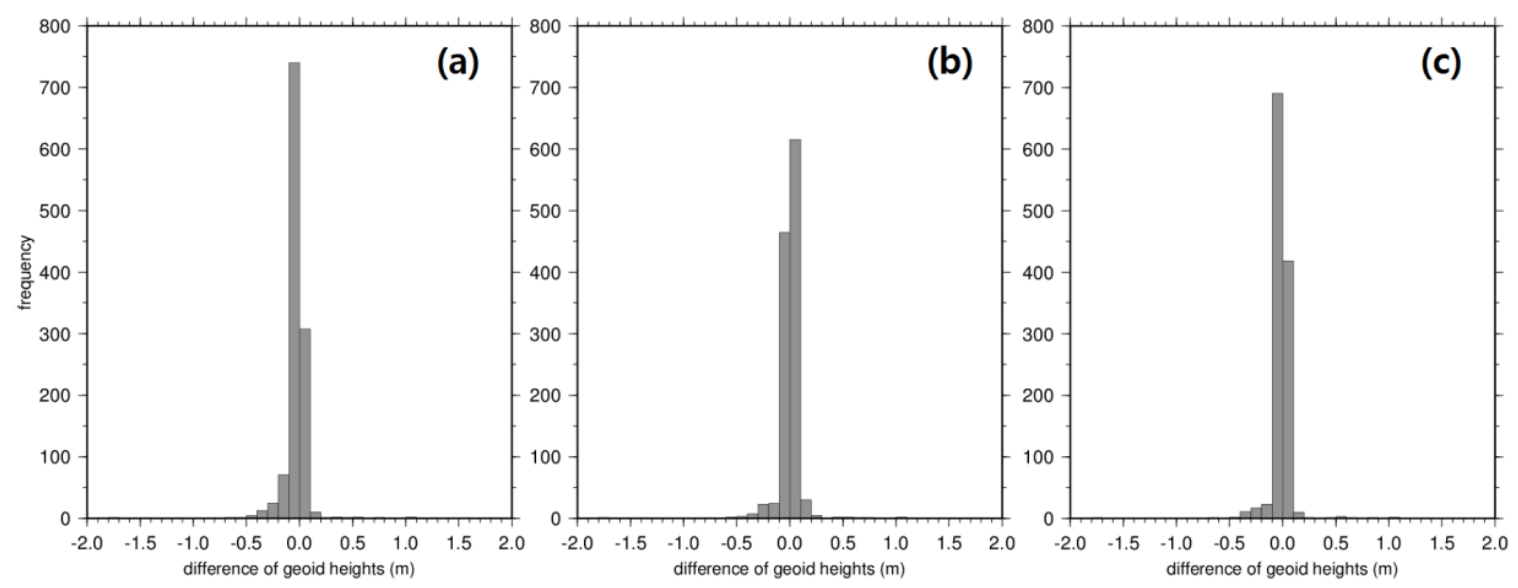

Figure 7. Histograms of the differences between the geoid heights $\left(N_{G N S S / l e v e l i n g}\right)$ derived from GNSS/leveling on the 1182 UCPs and the geoid heights $\left(N_{K N G e o i d}\right)$ derived from the three KNGeoid models. (a) KNGeoid13; (b) KNGeoid14; and (c) KNGeoid18.

\section{Conclusions}

In this study, the accuracy of the geoid heights derived from the recently released Earth gravity model based on gravity data calculated from the Gravity Recovery and Climate Experiment (GRACE) and the Gravity Field and Steady-State Ocean Circulation Explorer (GOCE) satellites was evaluated by comparing it with the geoid heights derived from the Global Navigation Satellite System (GNSS)/leveling on the 1182 unified control points (UCPs) installed by the National Geographic Information Institute (NGII) all over South Korea. The following conclusions were obtained in this study:

First The geoid heights derived from the three high-degree global geopotential models (GGMs) and the three Korean National Geoid (KNGeoid) models presented similar distributions ranging from 17 to $33 \mathrm{~m}$ around South Korea.

Second The EGM2008 model showed a rather stable result for the root-mean-square-error (RMSE) of the residuals $\left(N_{i}^{G N S S / l e v e l i n g}-N_{i}^{\text {Model }}\right)$ that were considered in this study in terms of relative geoid heights $\left(\Delta N_{i}\right)$ accuracy. Thus, the EGM2008 model is a more suitable model than the GECO and EIGEN-6C4 models as compared with the GNSS/leveling geoid heights all over South Korea. As a result, the EGM2008 model could be selected as the suitable GGM from among the three GGMs for determining a gravimetric geoid model for South Korea.

Third Among the three KNGeoid models, the most recently developed KNGeoid18 model showed better results as a gravimetric geoid model all over South Korea than the KNGeoid13 and KNGeoid14 models as compared with the GNSS/leveling-derived geoid heights.

For further study of the new gravimetric geoid model, it is necessary to perform an accuracy assessment of the geoid model all over South Korea by adding gravity data and by collocating the GNSS/leveling-derived geoid heights.

Author Contributions: Original idea and methodology, writing, and data analysis, K.B.K.; project administration and supervision, H.S.Y.; review and editing, H.J.C. All authors have read and agreed to the published version of the manuscript.

Funding: This work was supported by a National Research Foundation of Korea (NRF) grant funded by the South Korean government (MSIT) (NRF-2019R1C1C1005590).

Conflicts of Interest: The authors declare no conflict of interest. 


\section{References}

1. Lemoine, F.G.; Kenyon, S.C.; Factor, J.K.; Trimmer, R.G.; Pavlis, N.K.; Chinn, D.S.; Cox, C.M.; Klosko, S.M.; Luthcke, S.B.; Torrence, M.H.; et al. The Development of the Joint NASA GSFC and the National Imagery and Mapping Agency (NIMA) Geopotential Model EGM96; NASA Technical Paper; NASA/TP1998206 861; Goddard Space Flight Center: Greenbelt, MD, USA, 1998.

2. Reigber, C.; Schwintzer, P.; Stubenvoll, R.; Schmidt, R.; Flechtner, F.; Meyer, U.; König, R.; Neumayer, H.; Förste, C.; Barthelmes, F.; et al. A High Resolution Global Gravity Field Model Combining CHAMP and GRACE Satellite Mission and Surface Data: EIGEN-CG01C; Scientific Technical Report STR06/07l; GeoForschungsZentrum (GFZ): Potsdam, Germany, 2006.

3. Förste, C.; Flechtner, F.; Schmidt, R.; Meyer, U.; Stubenvoll, R.; Barthelmes, F.; Rothacher, M.; Biancale, R.; Bruinsma, S.; Lemoine, J.-M. A new high resolution global gravity field model from the combination of GRACE satellite mission and altimetry/gravimetry sur-face gravity data. In Proceedings of the EGU General Assembly, Vienna, Austria, 24-29 April 2005.

4. Pavlis, N.K.; Holmes, S.A.; Kenyon, S.C.; Factor, J.K. The development and evaluation of the Earth Gravitational Model 2008 (EGM2008). J. Geophys. Res. 2012, 117, B04406. [CrossRef]

5. Lee, S.B.; Lee, D.H. Evaluation of the topographic effect using the various gravity reduction methods for precise geoid model in Korea. In Proceedings of International Association of Geodesy Symposia, Crete, Greece, 23-27 June 2010; pp. 273-281.

6. Lee, S.B.; Kim, C.Y. Development of regional gravimetric geoid model and comparison with EGM2008 gravity-field model over Korea. Sci. Res. Essays 2012, 7, 387-397.

7. Baek, K.; Kwon, J.H.; Lee, J. Precision verification of new global gravitational model using GPS/leveling data. J. Kor. Soc. Surv. Geodesy Photogramm. Cartogr. 2013, 31, 239-247. [CrossRef]

8. Lee, S.B.; Auh, S.C.; Seo, D.Y. Evaluation of global and regional geoid models in South Korea by using terrestrial and GNSS data. KSCE J. Civ. Eng. 2017, 21, 1905-1911. [CrossRef]

9. Lee, S.B. Determination of precise regional geoid heights on and around mount Jiri, South Korea. J. Kor. Soc. Surv. Geodesy Photogramm. Cartogr. 2018, 36, 9-15.

10. Drinkwater, M.R.; Floberghagen, R.; Haagmans, R.; Muzi, D.; Popescu, A. GOCE: ESA's first Earth Explorer Core mission. In Earth Gravity Field from Space_From Sensors to Earth Sciences; Beutler, G., Drinkwater, M.R., Rummel, R., von Steiger, R., Eds.; Space Sciences Series of ISSI; Springer: Dordrecht, The Netherlands, 2003; Volume 17, pp. 419-432.

11. Tapley, B.D.; Bettadpur, S.; Watkins, M.; Reigber, C. The gravity recovery and climate experiment: Mission overview and early results. Geophys. Res. Lett. 2004, 31, L09607. [CrossRef]

12. Andersen, O.B. The DTU10 gravity field and mean sea surface. In Proceedings of the Second International Symposium of the International Gravity Field Service, Gravity Field of the Earth (IGFS2). Fairbanks, AK, USA, 20-22 September 2010.

13. Baek, K.; Lee, J.; Shin, K.; Kwon, J.H.; Moon, J. Construction and precision verification of Korean national geoid model KNGeoid13. In Proceedings of the 2014 Conference of the Korean Society of Surveying, Geodesy, Photogrammetry, and Cartography, Seoul, Korea, 24-25 April 2014; pp. 111-114.

14. Lee, J.; Kwon, J.H. Construction and precision verification of Korean national geoid model KNGeoid14. In Proceedings of the 2015 Conference of the Korean Society of Surveying, Geodesy, Photogrammetry, and Cartography, Masan, Korea, 23-24 April 2015; pp. 177-179.

15. Pail, R.l.; Fecher, T.; Barnes, D.; Factor, J.F.; Holmes, S.A.; Gruber, T.; Zingerle, P. Short note: The experimental geopotential model XGM2016. J. Geod. 2018, 42, 443-451. [CrossRef]

16. NGII. Establishment of National Geoid Model and Linked Model of Vertical Datum in Land and Marine; NGII Report; Publication No. 11-1613436-000166-01; National Geographic Information Institute: Suwon, Korea, 2018.

17. Förste, C.; Bruinsma, S.L.; Abrikosov, O.; Lemoine, J.-M.; Marty, J.C.; Flechtner, F.; Balmino, G.; Barthelmes, F.; Biancale, R. EIGEN-6C4 The latest combined global gravity field model including GOCE data up to degree and order 2190 of GFZ Potsdam and GRGS Toulouse. GFZ Data Serv. 2015. [CrossRef]

18. Gilardoni, M.; Reguzzoni, M.; Sampietro, D. GECO: A global gravity model by locally combining GOCE data and EGM2008. Stud. Geophys. Geod. 2016, 60, 228-247. [CrossRef] 
19. Ince, E.S.; Barthelmes, F.; Reißland, S.; Elger, K.; Förste, C.; Flechtner, F.; Schuh, H. ICGEM-15 years of successful collection and distribution of global gravitational models, associated services, and future plans. Earth Syst. Sci. Data 2019, 11, 647-674. [CrossRef]

20. Heiskanen, W.A.; Moritz, H. Physical Geodesy; W.H. Freeman: San Francisco, CA, USA, 1967.

21. Fotopoulos, G. An Analysis on the Optimal Combination of Geoid, Orthometric and Ellipsoidal Height Data. Ph.D. Thesis, University of Calgary, Calgary Canada, December 2003.

22. Kiamehr, R.; Sjöberg, L.E. Comparison of the qualities of recent global and local gravimetric geoid models in Iran. Stud. Geophys. Geod. 2005, 49, 289-304. [CrossRef]

23. Kotsakis, C.; Sideris, M.G. On the adjustment of combined GPS/levelling/geoid networks. J. Geod. 1999, 73, 412-421. [CrossRef]

24. Fotopoulos, G. Combination of Heights. In Geoid Determination: Theory and Methods; Sanso, F., Sideris, M.G., Eds.; Lecture Notes in Earth System Science; SpringerLink: Berlin/Heidelberg, Germany, 2013; pp. 517-544.

25. Wessel, P.; Smith, W.H.F.; Scharroo, R.; Luis, J.; Wobbe, F. Generic mapping tools: Improved version released. EOS Trans. Am. Geophys. Union 2013, 94, 409-410. [CrossRef]

C 2020 by the authors. Licensee MDPI, Basel, Switzerland. This article is an open access article distributed under the terms and conditions of the Creative Commons Attribution (CC BY) license (http://creativecommons.org/licenses/by/4.0/). 